\title{
23 PRODUCF̈̄ QNLINE

\section{MELHORIA CONTÍNUA DOS PROCESSOS E COMBATE AO DESPERDÍCIO ATRAVÉS DA FERRAMENTA QFD: O CASO DA METALÚRGICA}

\section{CONTINUOUS IMPROVEMENT PROCESS AND WASTE REDUCTION THROUGH A QFD TOOL: THE CASE OF A METALLURGIC PLANT}

\author{
Leoni Pentiado Godoy* E-mail: leoni godoy@yahoo.com.br \\ Alexandre Chapoval Neto** E-mail: alexandreacn@bol.com.br \\ Daniel Benitti Lorenzett* E-mail: dlorenzett@gmail.com \\ Édio Patric Guarienti* E-mail: edioguarienti@yahoo.com.br \\ *Universidade Federal de Santa Maria (UFSM), Santa Maria, RS \\ ** Sociedade Educacional Três de Maio (SETREM), Três de Maio, RS
}

Resumo: Este trabalho propõe a utilização do QFD para melhoria contínua dos processos produtivos e combate ao desperdício. Para coletar as informações empregou-se a observação simples e um questionário com perguntas fechadas aplicado aos colaboradores, representando $88,75 \%$ da população que atua nos processos produtivos de uma indústria do setor metal mecânico, localizada no Estado do Rio Grande do Sul. O QFD é um método eficiente de planejamento da qualidade, pelo fato de fornecer um diagnóstico da realidade que subsidia a definição de ações de melhoria com vistas ao combate do desperdício. Ações foram definidas proporcionando melhoria da comunicação entre os setores, possibilitando o fornecimento de produtos com especificações que atendem aos requisitos dos clientes, nos prazos e quantidades corretas, a um custo mínimo e plena satisfação das pessoas envolvidas com a empresa. A implementação dessas ações reduz os desperdícios, minimiza o trabalho adicional, maximiza o trabalho efetivo e aumenta a lucratividade.

Palavras-chave: Qualidade. Planejamento. Desperdícios. Melhoria continua. QFD.

\begin{abstract}
This paper proposes the use of QFD for the continuous improvement of production processes and waste reduction actions. To collect the information we used the simple observation and questionnaire with closed questions applied to employees, representing $88.75 \%$ of the population that works in the production processes of an industry of metal-mechanic sector, located in Rio Grande do Sul. QFD is an effective method of quality planning, because it provides a diagnosis that underpins the definition of improvement actions aimed at combating waste. Actions were set providing improved communication between the sectors, enabling the delivery of products with specifications that meet customer requirements, on time and the right amounts, at a minimum cost and satisfaction of those involved with the company. The implementation of these actions reduces waste, minimizes the extra work, maximizes effective labor and increases profitability.
\end{abstract}

Keywords: Quality. Planning. Waste. Continuous improvement. QFD.

\section{INTRODUÇÃO}

Produzir produtos com qualidade é uma atividade que envolve muitas variáveis, exigindo análise permanente do processo produtivo e gerencial. Para 
Paladini (2004) trata-se de uma ação dinâmica, onde são identificados elementos que surgem no ambiente interno ou externo e que precisam ser gerenciados para a melhoria contínua das atividades e, por consequência geram melhorias nos produtos.

É neste contexto que se apresenta o método QFD. Fundamenta-se em desdobrar os requisitos do consumidor transferi-los ao produto e aos procedimentos de produção, de modo a assegurar a satisfação dos usuários (AKAO, 1990). Entretanto, para atender satisfatoriamente a qualidade exigida pelo consumidor é necessário gerir a qualidade nas atividades produtivas das organizações. Para Neto (1992), os fatores que afetam a qualidade dos produtos são divididos em dois grupos: a tecnologia, composta pelos equipamentos, materiais e métodos de trabalho; e o grupo humano, do qual fazem parte os operadores, os supervisores e as demais pessoas da empresa.

Portanto, o presente trabalho tem como objetivo apresentar a utilização do método QFD, ouvindo e traduzindo a voz do cliente interno, para gerar ações de melhoria contínua nos processos produtivos de forma a combater o desperdício na indústria.

Para desenvolver a pesquisa tornou-se necessário apresentar a situação problemática que orientou os estudos teóricos e práticos acerca do assunto proposto. O presente estudo foi desenvolvido no intuito de reunir subsídios para responder a seguinte questão: o método QFD possibilita a definição de melhorias nas atividades de produção com vistas ao combate de desperdícios?

Nesta pesquisa, o diferencial da utilização do método QFD, reside no fato de valorizar o cliente interno como um elemento fundamental à garantia da qualidade dos produtos ofertados ao cliente externo.

\section{QUALITY FUNCTION DEPLOYMENT (QFD)}

O Desdobramento da Função Qualidade (QFD) constitui-se em um método interfuncional de apoio ao desenvolvimento de produtos e serviços, a partir da interpretação das necessidades e desejos dos clientes (AKAO, 1990; PINNA e CARVALHO, 2008; MIGUEL, 2009; LUCAS FILHO, PIO e FERREIRA, 2010; 
VOLPATO et al., 2010; PRASZKIEWICZ, 2011; VINODH e RATHOD, 2011; DIAS JUNIOR et al., 2012).

O desafio está em buscar a racionalização, modernização e competitividade, na qual, a qualidade é indispensável. Requer também, um esforço integrado de todas as fases do processo produtivo em virtude da responsabilidade na agregação de valor ao produto final. Neste contexto é que se apresenta o QFD (Quality Function Deployment), que traz métodos para otimizar as características do produto e a alocação de recursos (PRASZKIEWICZ, 2011). Trata-se de uma técnica de melhoria que trabalha os problemas de qualidade desde o início do projeto do produto até a fase de seu desenvolvimento, garantindo que as exigências dos clientes sejam traduzidas com precisão em requisitos técnicos que garantem a qualidade (AKAO, 1990; STEVENSON, 2007; HUAI, 2009; LIU, 2009; VINODH, e RATHOD, 2011).

O QFD é um método que procura assegurar a qualidade dos produtos a partir da identificação e desdobramento das exigências do cliente interno, relacionando as necessidades da qualidade "o que se espera" com os requisitos da qualidade (AKAO, 1990; FERNANDES e REBELATO, 2006; LUCAS FILHO, PIO e FERREIRA, 2010; PINTO e PAIVA, 2011; VINODH e RATHOD, 2011), trazendo benefícios ao processo de produção e atendendo a qualidade exigida pelo mercado.

O QFD é um método pouco explorado, que representa um bom campo de pesquisa, devendo levar em consideração as variáveis internas e externas e suas ligações que afetam o processo de decisão (OSORIO, ARANGO e RUALES, 2011; DIAS JUNIOR et al., 2012).

Para atingir os requisitos competitivos as empresas precisam desenvolver meios para ouvir os clientes, assimilando rapidamente essas informações, tendo no QFD uma ferramenta para sistematizar e transformar os desejos do consumidor em características técnicas de produtos (MIGUEL, 2009; NINOSKA et al., 2009; LUCAS FILHO, PIO e FERREIRA, 2010; PINTO e PAIVA, 2011; PRASZKIEWICZ, 2011; VINODH e RATHOD, 2011). O QFD é uma importante metodologia para traduzir a voz do cliente (subjetiva) em requisitos mensuráveis (objetivos) que permeiam e orientam todas as fases do processo de desenvolvimento de produtos e serviços garantindo a satisfação do cliente (AKAO, 1990; CARNEVALLI e MIGUEL, 2007). 
No Brasil, vários artigos e livros já foram públicos acerca da aplicação do método QFD, como por exemplo: Akao (1990), Miguel (2003), Carvenalli, Miguel e Calarge (2003), Nascimento (2003), Wagner (2004); Cheng e Melo Filho (2007). No entanto, a grande maioria das empresas brasileiras ainda não conhece $e$, consequentemente, deixa de utilizar o potencial e as vantagens do emprego desta metodologia.

O QFD está subdividido em Desdobramento da Qualidade (QD) e Desdobramento da Função Qualidade no sentido restrito (QFDr) (AKAO, 1990; CHENG e MELO FILHO, 2007; MELO FILHO e CHENG, 2007). O QD pode ser entendido como o desdobramento da qualidade, utilizando a lógica de causa e efeito, partindo-se da voz do cliente para definir as características de qualidade dos produtos, de forma a alcançar um valor que será entendido como parâmetro de controle e o QFDr é conhecido por Desdobramento da Função do Trabalho objetiva especificar o que precisa ser realizado para se obter a qualidade projetada que satisfaça as necessidades dos clientes (AKAO, 1990; CHENG, 2003; CHENG e MELO FILHO, 2007). Os autores citados conceituam como um processo sistemático de desdobramento do trabalho da ação gerencial de planejamento da qualidade (Gestão do Desenvolvimento do Produto) em procedimentos gerenciais e técnicos para serem cumpridos pelas áreas funcionais da empresa.

Cheng e Melo Filho (2007), descrevem que na parte do QFDr ou desdobramento do trabalho, o método QFD trata da forma mais eficaz e eficiente, ou pelo menos, quais são as melhores alternativas, de assegurar a qualidade requerida através do emprego de trabalho humano e de equipamentos disponíveis.

Portanto, se no QD efetua-se o desdobramento da qualidade exigida pelo cliente por meio da construção da matriz da qualidade, no QFDr realiza-se o planejamento dos meios para atingir a qualidade projetada, considerando os recursos disponíveis.

\section{PROCEDIMENTOS METODOLÓGICOS}

O presente estudo foi classificado como estudo de caso, pois descreve uma aplicação prática do método QFD, em uma única organização, fornecendo conhecimento aprofundado de uma determinada realidade. Concomitante ao estudo 
de caso ocorreu um trabalho de pesquisa-ação. Esta situação fica evidente durante o desenvolvimento da pesquisa, pois neste estágio do trabalho o pesquisador se caracteriza como um colaborador do processo, pois não ocorre o simples levantamento dos dados, mas sim há uma efetiva interferência na realidade dos fatos observados.

Para realizar esta pesquisa se utilizaram as etapas descritas na sequência.

Etapa 1 - Após a seleção da empresa partiu-se para a formação da equipe de trabalho que operacionalizou a pesquisa, era composta por representantes da Área de Produção: de corte, dobra, usinagem, solda, montagem, pintura e controle da qualidade.

Etapa 2 - A equipe empregou a técnica do Brainstorming para gerar as ideias nas reuniões com os vários participantes da equipe. A coordenação dos trabalhos foi realizada pelo autor da pesquisa e pelo coordenador da produção.

Etapa 3 - A equipe organizou o Quadro 1, com as descrições das áreas que compõe os principais processos que são: administrativo, negócios e industrial. Para cada área foi feita a descrição e definidas as suas principais atividades (Quadro 1).Também o Quadro 2 apresenta a descrição dos subprocessos. Além do pesquisador organizar a Figura 1 para conhecer as interações que ocorriam entre os processos.

Etapa 4 - A fim de agrupar as ideias levantadas no Brainstorming utilizou-se o método $\mathrm{KJ}$, que consiste em sistematizar e hierarquizar as informações por afinidade. Com base neste método as ideias levantadas pelo grupo foram organizadas, formando níveis, considerando a afinidade dos registros.

Etapa 5 - para a coleta das informações empregaram-se outras duas ferramentas importantes: observação simples e questionário com perguntas fechadas. O questionário foi útil na avaliação de dois aspectos fundamentais: grau de importância atribuído pelo colaborador para cada requisito de qualidade identificado e, condições atuais de cada exigência nas atividades produtivas da organização.

Foram distribuídos 80 questionários aos colaboradores que atuam no processo de produção, destes obteve-se o retorno de 71 , o que representa $88,75 \%$ das avaliações entregues. 
Etapa 6 - para a análise e interpretação dos dados, foi construído um modelo conceitual. O modelo conceitual é formado pelo conjunto de tabelas e matrizes de um determinado desenvolvimento (CHENG, 2007). Este desenvolvimento pode estar relacionado a qualquer produto ou serviço.

A estruturação do modelo conceitual segue a lógica dos sistemas: entrada, processo e saída. A estruturação é encaminhada considerando o resultado final que se deseja obter. Portanto, o percurso percorrido pelas tabelas e matrizes visa fundamentalmente à qualidade do produto final.

Considera-se que algumas decisões metodológicas estão diretamente relacionadas à escolha da abordagem mais adequada ao endereçamento da questão de pesquisa, enquanto que outras decisões são relativas aos procedimentos e condução.

O presente estudo constitui-se em um trabalho particular, não podendo ser inteiramente reaplicado em outras situações, pois tanto o modelo conceitual quanto as tabelas e matrizes são específicos para cada contexto.

\section{AMBIENTE DE PESQUISA}

A empresa em estudo atua no ramo de produção de peças para máquinas, implementos agrícolas e rodoviários. Os produtos têm como destinação montadoras que os comercializam no mercado interno brasileiro e também, para vários países de diferentes continentes. Internamente a empresa é gerida por três áreas: administrativo, negócios e industrial, (Quadro1). 
Quadro 1 - Descrição dos principais processos

\begin{tabular}{|c|c|c|c|}
\hline \multirow{2}{*}{ Processo } & \multirow{2}{*}{ Descrição } & \multicolumn{2}{|c|}{ Principais Atividades } \\
\hline & & Entrada de Informações & Saída de Informações \\
\hline 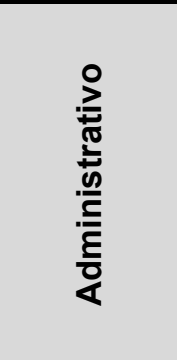 & 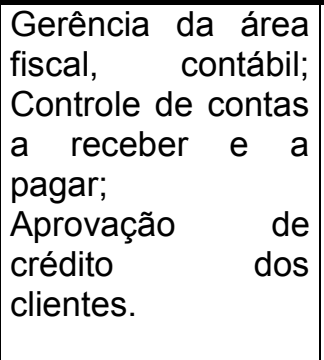 & $\begin{array}{l}\text { Necessidade de máquinas e } \\
\text { equipamentos; Orçamentos } \\
\text { aprovados; Estabelecimento } \\
\text { de metas; Decisões gerenciais; } \\
\text { Contratação/demissão de mão } \\
\text { de obra especializada; Contato } \\
\text { com cliente; Duplicatas a } \\
\text { receber/ pagar; Análise de } \\
\text { novos clientes. }\end{array}$ & $\begin{array}{l}\text { Orçamentos; Metas (reunião } \\
\text { de análise crítica); Entrevista, } \\
\text { seleção, compras e e } \\
\text { informações dos clientes; } \\
\text { Descontar, pagar duplicatas, } \\
\text { aprovação ou não de clientes. }\end{array}$ \\
\hline 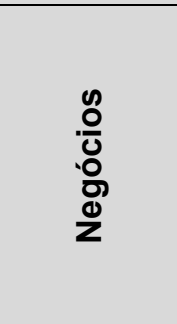 & \begin{tabular}{|lr} 
Responsável & pelo \\
planejamento dos \\
setores de vendas, \\
compras, \\
suprimentos & e \\
logística e seus \\
respectivos \\
subprocessos.
\end{tabular} & $\begin{array}{l}\text { Lista de matéria prima } \\
\text { necessária à produção; } \\
\text { Cadastro de fornecedores } \\
\text { aprovados na lista; Ordem de } \\
\text { compra; Ideias de clientes. }\end{array}$ & $\begin{array}{ll}\text { Realização } & \text { da } \\
\text { Avaliação ou reavaliação de } \\
\text { fornecedores. }\end{array}$ \\
\hline 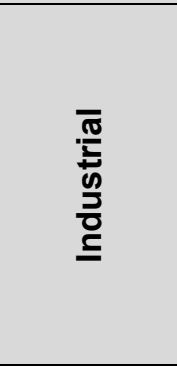 & \begin{tabular}{|l|} 
Responsável por \\
planejar, organizar, \\
dirigir e controlar a \\
produção e seus \\
respectivos \\
processos \\
produtivos.
\end{tabular} & $\begin{array}{lcc}\text { Análise de } & \text { necessidade de } \\
\text { compra de matéria prima; } \\
\text { Emenda } & \text { de pedido, } \\
\text { quantidade; Previsão de } \\
\text { entrega do fornecedor; } \\
\text { Previsão de entrega para o } \\
\text { cliente; Sugestões para o } \\
\text { produto; Informações dos } \\
\text { clientes. }\end{array}$ & 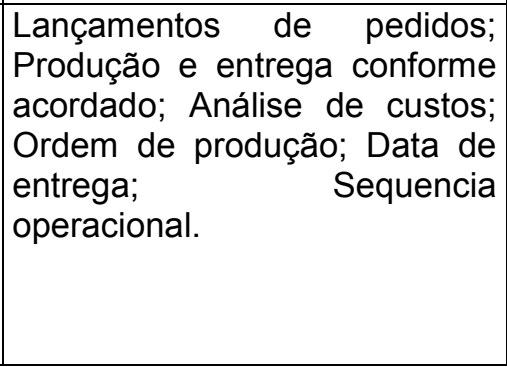 \\
\hline
\end{tabular}

Fonte: Pesquisa (2010)

As interações que ocorrem entre os processos da empresa estudada podem ser visualizadas na Figura 1. Os processos planejados pela organização devem estar claramente definidos e integrados, e também desdobrados de forma eficiente, sendo geridos e melhorados continuamente. Eles acabam sendo elementos chave tanto para a tomada de decisão quanto para ações corretivas na geração de indicadores de desempenho. Assim é imperativo empregar meios adequados para gerenciar as interações e as sequencias entre os processos.

Os processos por sua vez estão divididos em subprocessos (Quadro 2), que são constituídos por conjuntos de atividades correlacionadas, que executam uma parte específica do processo, do qual recebe insumos e para o qual envia o produto do trabalho realizado por todas as atividades. 
Figura 1 - Interação entre os processos

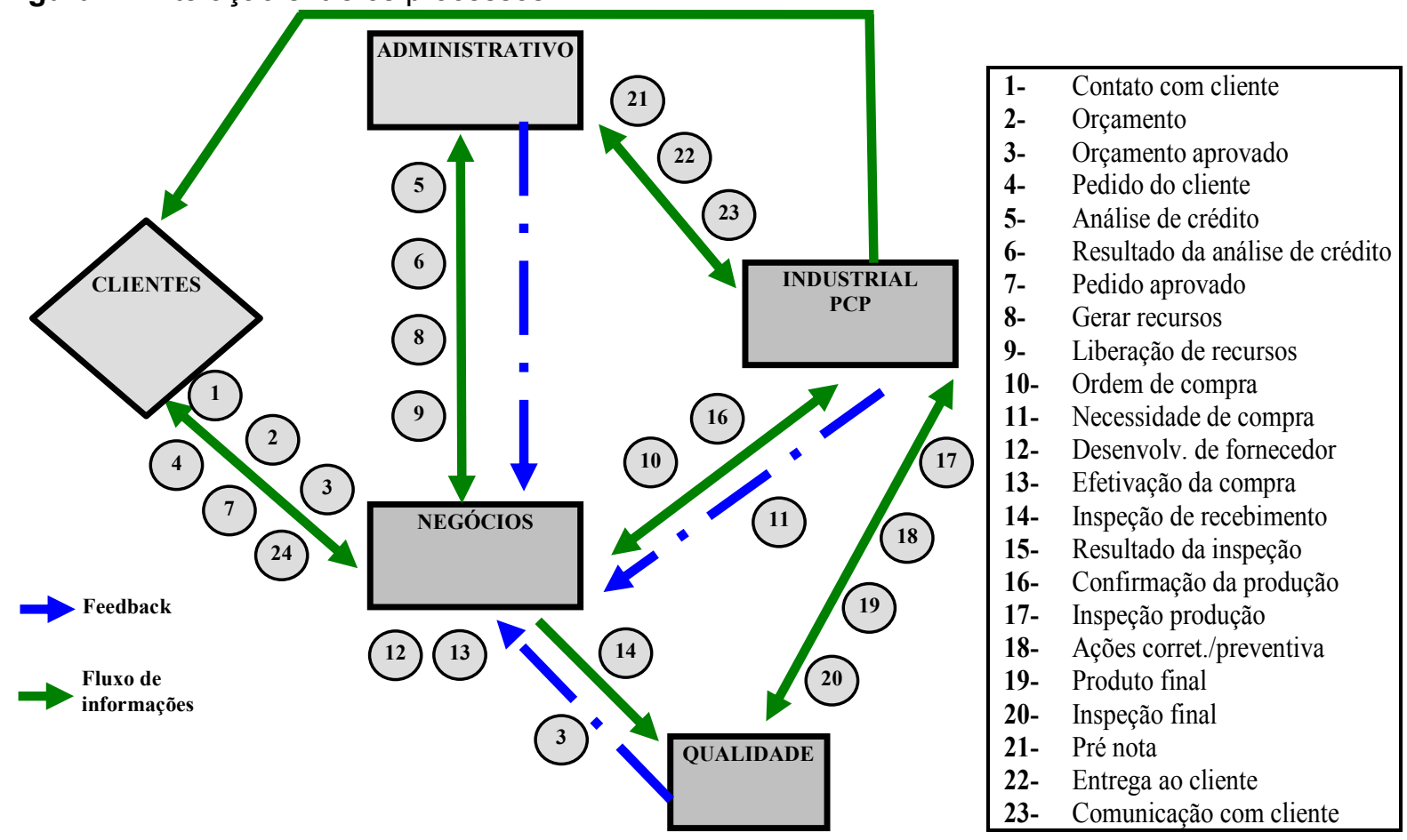

Fonte: Pesquisa (2010)

Quadro 2 - Descrição dos subprocessos da organização

\begin{tabular}{|c|c|c|}
\hline Subprocesso & Descrição & Principais Atividades \\
\hline Vendas & $\begin{array}{l}\text { Visa o controle e análise dos pedidos do } \\
\text { cliente; possibilidade de fabricação, preço e } \\
\text { prazo. }\end{array}$ & $\begin{array}{l}\text { Conhecimento dos processos, } \\
\text { capacidade produtiva da empresa e } \\
\text { programas. }\end{array}$ \\
\hline Suprimentos & $\begin{array}{l}\text { Aquisição de matéria prima e serviços; } \\
\text { Inspeção de recebimento da matéria prima e } \\
\text { componentes relevantes para o produto; } \\
\text { Controle de estoque e processo terceirizado. }\end{array}$ & $\begin{array}{l}\text { Realização de compra; Avaliação ou } \\
\text { reavaliação de fornecedores; } \\
\text { Identificação do produto; Análise de } \\
\text { processos que são terceirizados. }\end{array}$ \\
\hline Logística & $\begin{array}{l}\text { Define o transporte interno e externo da } \\
\text { empresa. }\end{array}$ & Transporte interno; Transporte externo. \\
\hline $\begin{array}{l}\text { MEPRO } \\
\text { (Métodos e } \\
\text { Processos) }\end{array}$ & $\begin{array}{l}\text { Planejar e desenvolver os processos } \\
\text { necessários para a realização do produto. }\end{array}$ & $\begin{array}{l}\text { Definir os processos para otimizar a } \\
\text { produção. }\end{array}$ \\
\hline $\begin{array}{l}\text { PCP - } \\
\text { (Planejamento } \\
\text { e Controle da } \\
\text { Produção) }\end{array}$ & $\begin{array}{l}\text { Processo que interliga: compras x produção x } \\
\text { vendas; Controla a produção, custos e } \\
\text { orçamentos. }\end{array}$ & $\begin{array}{l}\text { Lançamento de pedidos; Controle da } \\
\text { Produção e entrega; Análise de custos; } \\
\text { Ordem de produção; Data de entrega; } \\
\text { Sequência operacional. }\end{array}$ \\
\hline Produção & $\begin{array}{l}\text { Transformação da matéria-prima em produto } \\
\text { com processos monitorados e inspecionados } \\
\text { através de procedimentos, instruções de } \\
\text { trabalho e sequência operacional. }\end{array}$ & $\begin{array}{l}\text { Ordem de serviço que contem: data de } \\
\text { entrega, quantidade, tipo de matéria- } \\
\text { prima e operações. }\end{array}$ \\
\hline $\begin{array}{l}\text { Gestão de } \\
\text { pessoas }\end{array}$ & $\begin{array}{l}\text { Recrutamento e seleção de pessoas, além de } \\
\text { passar todas as informações cabíveis para os } \\
\text { novos colaboradores; Elaboração de plano } \\
\text { anual de treinamento. }\end{array}$ & $\begin{array}{l}\text { Seleção de currículos para contratar } \\
\text { novos colaboradores; Necessidade de } \\
\text { treinamentos; Execução das rotinas de } \\
\text { Rh. }\end{array}$ \\
\hline Serviços/Apoio & $\begin{array}{l}\text { Responsável pela segurança, atendimento, } \\
\text { comunicação, suporte para sistema } \\
\text { informatizado, organização e limpeza. }\end{array}$ & Comunicação interna e externa. \\
\hline
\end{tabular}

Fonte: Pesquisa (2010) 
O subprocesso de produção possui uma série de atividades que formam um conjunto de procedimentos executados a fim de produzir determinados resultados. As atividades do subprocesso produção e suas respectivas tarefas podem ser observadas no Quadro 3.

Quadro 3 - Descrição dos subprocessos de produção

\begin{tabular}{|c|c|c|}
\hline \multicolumn{3}{|c|}{ Subprocesso Produção } \\
\hline Atividades & \multicolumn{2}{|r|}{ Tarefas } \\
\hline Expedição & \multicolumn{2}{|c|}{$\begin{array}{l}\text { Receber matéria prima do fornecedor; Separar matéria prima para início aos } \\
\text { processos; Anexar os desenhos das peças à matéria prima; Encaminhar produto } \\
\text { acabado para o cliente. }\end{array}$} \\
\hline Usinagem & \multicolumn{2}{|c|}{ Realizar serviço de torno, furadeira, mandrilhadora e serra. } \\
\hline Estamparia & \multicolumn{2}{|l|}{ Realizar serviço de estampa. } \\
\hline Dobra & \multicolumn{2}{|c|}{ Realizar serviço de guilhotina, Realizar serviço de dobragem. } \\
\hline Montagem & \multicolumn{2}{|c|}{$\begin{array}{l}\text { Colocar peças e conjuntos em posição para soldagem; Montar chassis; Verificar } \\
\text { cotas. }\end{array}$} \\
\hline Solda & \multicolumn{2}{|c|}{ Realizar serviço de solda; Retirar cordões de soldas para eventuais retrabalhos. } \\
\hline Rebarbagem & \multicolumn{2}{|c|}{$\begin{array}{l}\text { Retirar respingo de solda; Retirar pontos de solda; Rebarbar chapas que foram } \\
\text { trabalhadas; Fazer acabamentos para melhorar a estética do produto. }\end{array}$} \\
\hline Pintura & \multicolumn{2}{|c|}{ Aplicar fundo; Pintar; Realizar acabamento de pintura. } \\
\hline $\begin{array}{l}\text { Montagem } \\
\text { final }\end{array}$ & \multicolumn{2}{|c|}{ Realizar a montagem dos subconjuntos; Realizar a montagem da usina. } \\
\hline \multirow{4}{*}{ Qualidade } & $\begin{array}{l}\text { Recebimento da matéria- } \\
\text { prima }\end{array}$ & $\begin{array}{l}\text { Verificar conformidade da matéria prima; Verificar } \\
\text { especificação da matéria prima; Verificar apresentação } \\
\text { da matéria-prima. }\end{array}$ \\
\hline & Montagem & Verificar cotas; Verificar dimensões. \\
\hline & Solda & $\begin{array}{l}\text { Verificar cordões de solda; Verificar estética do cordão } \\
\text { de solda. }\end{array}$ \\
\hline & Pintura & $\begin{array}{l}\text { Verificar pintura; Fazer inspeção final; Autorizar } \\
\text { liberação para entrega ao cliente. }\end{array}$ \\
\hline
\end{tabular}

Fonte: Pesquisa (2010)

Para verificar a sequencia das atividades do processo de produção utilizou-se o fluxograma, permitindo uma visão integrada do processo; a visualização de detalhes críticos do processo; a identificação do fluxo do processo e das interações entre os subprocessos; a identificação dos pontos de controle potenciais e; a identificação de inconsistências e pontos frágeis. O fluxograma das atividades produtivas, desde a chegada da matéria prima até a expedição do produto acabado (Figura 2).

O primeiro estágio do processo de produção é o recebimento da matériaprima do fornecedor pelo Setor da Qualidade que verifica a apresentação, especificação e conformidade. A matéria prima em conformidade com as especificações é encaminhada à próxima atividade do processo: usinagem; dobra e corte. Há peças que são trabalhadas somente pela atividade do corte e outras que, 
além do corte, são usinadas e dobradas. A distribuição da matéria-prima para o início da produção é feita de acordo com a primeira atividade a ser executada, sendo que a partir daí segue o fluxo normal da produção.

As chapas depois de cortadas, usinadas e dobradas são encaminhadas para a montagem. Nesta etapa, as peças e conjuntos são dispostos em suas posições conforme definido no projeto. Para a disposição das peças e conjuntos a equipe de montagem utiliza gabaritos e instrumentos de medição. Na montagem são utilizados os desenhos industriais para o correto dimensionamento de cotas e posições das peças e conjuntos. Quando as peças e componentes estão montados em suas posições, o Setor da Qualidade de posse de um plano de inspeção faz uma verificação para examinar se as peças e componentes estão acoplados nas posições corretas, segundo as especificações do projeto.

Como forma de controle, o Setor da Qualidade disponibiliza aos encarregados das atividades de montagem, solda e pintura, planos de inspeção que devem ser preenchidos e assinados, informando sobre a realização das inspeções. Este plano de inspeção é confeccionado com base no projeto do fornecedor e nas não conformidades encontradas em inspeções anteriores. Mesmo assim, quando o Setor da Qualidade detecta não conformidades nas inspeções, retrabalhos precisam ser feitos.

Na próxima etapa do processo a equipe, solda as peças e conjuntos, após o Setor da Qualidade faz uma nova inspeção para verificar as dimensões dos cordões de solda, a estética do produto e se o processo de fusão uniu os componentes conforme determinado no projeto. Ainda, ocorre a atividade de rebarbagem para retirada dos respingos, pontos de solda, acabamento dos cantos e conjuntos. Após, as peças e conjuntos são pintados e o Setor da Qualidade faz a inspeção e autoriza a montagem final do produto e novamente é inspecionado, estando em conformidade é liberado para expedição e encaminhado ao cliente. Observa-se que apesar da realização de várias inspeções durante todo o processo produtivo, no momento da inspeção final para liberação é possível verificar ainda, a existência de algumas não conformidades e a necessidade de retrabalhos.

No processo produtivo ocorrem falhas que comprometem a qualidade e produtividade do processo, sendo necessária a tomada de algumas providências para evitar que esses tipos de erros aconteçam.

Revista Produção Online, Florianópolis, SC, v.13, n. 2, p. 417-449, abr./jun. 2013. 
Figura 2 - Fluxograma do processo produtivo

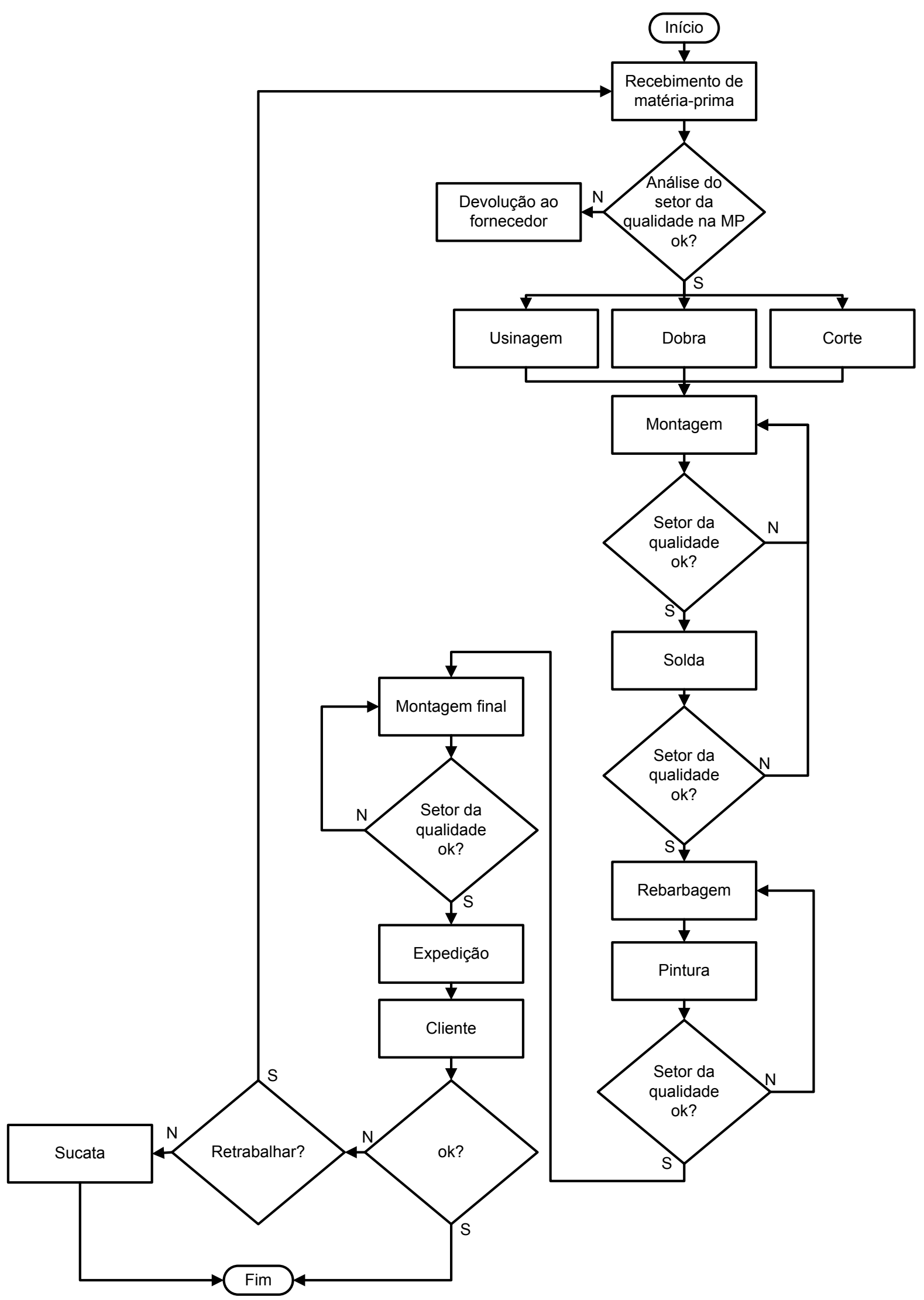

Fonte: Pesquisa (2010)

Revista Produção Online, Florianópolis, SC, v.13, n. 2, p. 417-449, abr./jun. 2013. 
Estes problemas provocam atrasos na produção e o desperdício de matéria prima, mão de obra, solda, máquina e equipamentos, aumentando com isso os custos e diminuindo a competitividade da empresa no mercado.

\section{MODELO CONCEITUAL, METODOLOGIA DO QFD E COMPOSIÇÃO DAS MATRIZES}

O QFD se apresenta como método eficiente de conversão dos requisitos de qualidade em ações técnicas de melhoria, permitindo a introdução dos desejos dos clientes nos projetos dos produtos possibilitando a fabricação de itens confiáveis, que atendam as exigências do mercado (AKAO, 1990; FERNANDES e REBELATO, 2006; CHENG e MELO FILHO, 2007).

O modelo conceitual do QFD pode ser definido como o caminho por onde o desenvolvimento do projeto deve percorrer para atingir as metas estabelecidas (CHENG e MELO FILHO, 2007). O modelo inclui quatro matrizes, que são respectivamente: qualidade exigida é o primeiro grupo constituído por fatores relacionados ao projeto detalhado do produto, o segundo grupo é composto pelos fatores relacionados ao projeto do processo, planejamento do produto, e planejamento da produção (AKAO, 1990; CHAN e WU, 2005; LIU, 2009), desenvolvimento que está relacionado a qualquer produto ou serviço. O modelo conceitual explicita o objetivo que se pretende atingir e, todos os envolvidos no trabalho possibilitando uma visão holística do sistema. O modelo que norteou o trabalho visando à definição de melhorias no processo de produção e redução de desperdícios está na Figura 3.

De acordo com a proposta do QFD, procurou-se sequenciar o desenvolvimento das tabelas e matrizes de acordo com a voz do consumidor, que corresponde aos clientes internos, agentes das atividades de produção, que vivem diariamente a realidade do processo e possuem relação direta com a qualidade do produto final.

Entendeu-se que, os subsídios para definir sugestões de melhoria na qualidade das atividades de produção partem da avaliação das condições atuais, e da importância atribuída à estrutura, processos de produção, recursos humanos e matéria prima empregada na geração dos produtos finais. Ressalta-se, que a 
abordagem deste artigo limita-se a processos e matéria-prima, deixando estrutura e recursos humanos para trabalhos futuros.

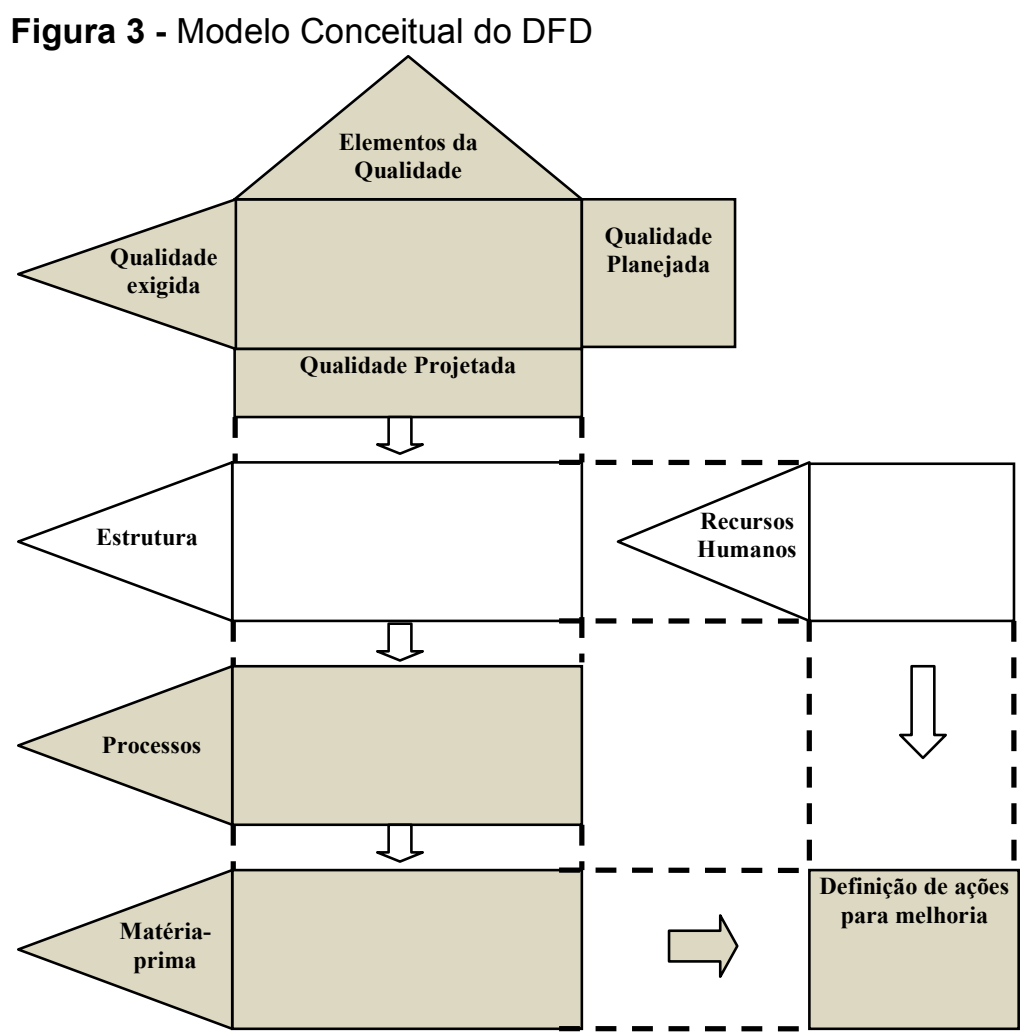

Fonte: Adaptado de Akao (1990)

Os resultados obtidos na aplicação do QFD além de criarem informações úteis para o planejamento do produto e para sua produção também reduzem os tempos do processo e de ciclo de produção, diminuindo custos e evitando perdas (AKAO, 1990; FINCH, 2003; CHAN e WU, 2005; KRAJEWSKI et al., 2007, LIU, 2009). O modelo conceitual mostra a sequência correta das análises através de quadros e tabelas. A Figura 3 mostra a qualidade exigida, sendo a primeira etapa é mostrada no Quadro 4, que converte a linguagem do cliente para a linguagem do projeto, após é estruturado o Quadro 5, com o desdobramento da qualidade exigida dos processos e matéria prima.

$\mathrm{Na}$ sequência o Quadro 6, desdobramento dos elementos da qualidade (processos e matéria prima), sendo a partir desses Quadros que foi elaborada a Matriz da Qualidade uma para Processos e outra para Matéria Prima. Assim que, o modelo conceitual, mostra esse desenvolvimento na parte superior da Figura 3 e na parte inferior temos os elementos analisados Processos e Matéria Prima concluindo Revista Produção Online, Florianópolis, SC, v.13, n. 2, p. 417-449, abr./jun. 2013. 
com a definição de ações e melhoria. A maior preocupação da administração da empresa era com o processo e matéria prima, considerados os pontos mais críticos. Atualmente, já foi aplicado o QFD na estrutura e recursos humanos trazendo novos resultados a pesquisa, sendo completada a implementação do QFD na empresa como um todo.

\subsection{Ouvindo e traduzindo a voz do cliente: a qualidade exigida}

O QFD pode ser usado como uma ferramenta para priorizar as direções importantes que oferecem um potencial de melhoria de acordo com o desejo dos clientes. Assim o QFD pode ser encarado como um método sistemático para apoiar o processo de tomada de decisão (AKAO, 1990; LEE et al., 2000; YANG et al., 2003; LUU et al., 2009). O comprometimento das pessoas no desenvolvimento das atividades de produção mostra resultados surpreendentes. Esta compreensão irá criar as precondições para que cada colaborador possa assumir suas próprias responsabilidades adotando medidas preventivas de melhorias, eliminando desperdícios de recursos de manufatura e agregando valor ao produto. Traduzindo as informações do cliente em ações concretas pode render resultados consideráveis para as empresas. A conversão da voz do cliente é requisito fundamental para a estruturação das tabelas e matrizes, traduzindo as exigências e características de qualidade.

Todas as informações coletadas e compiladas servem de subsídio às decisões de melhoria da qualidade (FERNANDES e REBELATO, 2006; CHENG e MELO FILHO, 2007; PINTO e PAIVA, 2011). Segundo Akao (1996), os requisitos de qualidade devem ser expressos de maneira concisa para que não haja mais de um significado, utilizando ao máximo a própria linguagem dos clientes, evitando o uso de expressões técnicas. A técnica apropriada para a sistematização das informações depende do que se deseja e do orçamento disponível.

Tomando-se por base os pressupostos estabelecidos no modelo conceitual e o fato de o QFD ser indicado como uma atividade desenvolvida em equipe, a identificação dos requisitos de qualidade nas atividades de produção foi realizada através da ferramenta brainstorming. Ferramenta que estimulou a participação de 
todos os envolvidos, permitindo que um grande número de ideias fosse exposto em um curto espaço de tempo.

\subsection{Conversão das exigências de qualidade em requisitos de qualidade exigida}

$\mathrm{Na}$ estruturação do método QFD, a partir dos itens exigidos, identificados junto aos clientes, torna-se necessário encontrar informações linguísticas relativas à qualidade, que sejam expressas de modo claro e simples, evitando termos com duplo sentido e baixo grau de abstração, pois estas irão compor as qualidades exigidas (OHFUJI, ONO e AKAO, 1990).

Segundo Cheng e Melo Filho (2007), quanto ao cliente interno da empresa, a tabela da qualidade exigida é composta pelas exigências das pessoas que trabalham para a empresa. A voz do cliente interno é mais fácil de ser obtida e transformada, em necessidades de melhoria do processo produtivo. As pessoas das organizações possuem uma linguagem afim, e muitas vezes, as informações coletadas são as próprias qualidades exigidas, não necessitando de um desdobramento.

De acordo com a estrutura proposta no modelo conceitual, realizou-se o trabalho de aprimoramento da conversão das exigências de qualidade da linguagem, apresentada pelos integrantes da equipe de trabalho, em requisitos de qualidade exigida. A linguagem foi modelada para melhor entendimento e para posterior estratificação, avaliação e compilação, durante a estruturação da matriz da qualidade (Quadro 4). 
Quadro 4 - Conversão da linguagem do cliente interno para a linguagem do projeto

\begin{tabular}{|c|c|c|c|}
\hline \multirow{8}{*}{\multicolumn{2}{|c|}{$\begin{array}{l}0 \\
0 \\
\mathscr{y} \\
d_{0} \\
0 \\
0 \\
0 \\
0\end{array}$}} & Requisitos de qualidade exigida & Exigência de qualidade \\
\hline & & Padronização dos métodos de trabalho & Padronização dos métodos de trabalho \\
\hline & & Instruções de trabalho & Ter instruções de trabalho \\
\hline & & Disciplina em seguir os métodos de trabalho & $\begin{array}{l}\text { Disciplina para seguir os métodos de } \\
\text { trabalho }\end{array}$ \\
\hline & & Pontos de controle & Ter pontos de controle \\
\hline & & Indicadores de desempenho & Ter indicadores de desempenho \\
\hline & & Plano de produção & Ter plano de produção com antecedência \\
\hline & & Plano de inspeção & $\begin{array}{l}\text { Ter plano de inspeção no recebimento da } \\
\text { matéria prima; } \\
\text { Ter plano de inspeção nos pontos críticos de } \\
\text { controle; } \\
\text { Ter plano de inspeção para expedição do } \\
\text { produto pronto. }\end{array}$ \\
\hline 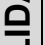 & & Requisitos de qualidade exigida & Exigência de qualidade \\
\hline$\frac{1}{\frac{1}{\alpha}}$ & $\stackrel{\pi}{\varepsilon}$ & $\begin{array}{l}\text { Qualidade da matéria prima para } \\
\text { transformação }\end{array}$ & $\begin{array}{l}\text { Apresentação da matéria prima; } \\
\text { Matéria prima em conformidade com a } \\
\text { especificação }\end{array}$ \\
\hline & 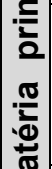 & $\begin{array}{l}\text { Quantidade de matéria-prima para } \\
\text { transformação }\end{array}$ & $\begin{array}{l}\text { Matéria prima na quantidade certa; } \\
\text { Aquisição de matéria prima em tempo hábil; } \\
\text { Matéria prima disponível para início do } \\
\text { processo. }\end{array}$ \\
\hline & $\sum^{10}$ & $\begin{array}{l}\text { Prazo de entrega da matéria prima pelos } \\
\text { fornecedores externos }\end{array}$ & $\begin{array}{lllll}\begin{array}{l}\text { Entregas } \\
\text { externos }\end{array} & \text { no } & \text { prazo } & \text { dos } & \text { fornecedores } \\
\end{array}$ \\
\hline & & $\begin{array}{l}\text { Prazo de entrega da matéria prima pelos } \\
\text { fornecedores internos }\end{array}$ & Entregas no prazo dos fornecedores internos \\
\hline
\end{tabular}

Fonte: Pesquisa (2010)

\subsection{Matriz da qualidade}

A Matriz da Qualidade é geralmente, a primeira a ser construída em um trabalho de QFD, dando visibilidade às informações. A Matriz foca o desenvolvimento do produto em prol do cumprimento dos requisitos ou necessidades dos clientes. A estruturação sistematiza as qualidades exigidas pelos clientes e expressa a correlação existente entre os requisitos e os elementos de qualidade. É o resultado da união em forma de matriz de duas tabelas distintas: a Tabela de Desdobramento da Qualidade Exigida e a Tabela de Desdobramento dos Elementos da Qualidade. Assim, é considerada matriz, porque os itens de qualidade exigida possuem correlação com alguns elementos de qualidade.

Esta correlação é indicada marcando os itens que guardam esta relação com um círculo ou com outro símbolo qualquer (AKAO, 1996). A elaboração da matriz da qualidade expressa o caráter de subdivisão e unificação, pois se percebe a classificação das exigências de qualidade desde o nível mais específico até o agrupamento em grupos macros.

Revista Produção Online, Florianópolis, SC, v.13, n. 2, p. 417-449, abr./jun. 2013. 
A partir dos dados obtidos na correlação realizada, é estabelecida a qualidade planejada, que fornece o subsídio para a definição dos planos de trabalho. É importante salientar que a ênfase está no procedimento e não no uso da matriz, que é apenas uma ferramenta para melhor dispor e processar as informações.

\subsection{Desdobramento dos requisitos de qualidade}

A tabela de desdobramento da qualidade exigida consiste na representação das verdadeiras exigências dos clientes, o mais próximo possível de sua própria linguagem. Exigências, que são obtidas de várias fontes de informação, são sintetizadas de forma sistemática e desdobradas do nível abstrato para o concreto, e do resumido para o detalhado (CHENG e MELO FILHO, 2007). Este Quadro é construído sistematicamente pela determinação do produto objeto e identificação das exigências do mercado (AKAO, 1996). O objetivo da sistematização é organizar hierarquicamente as exigências dos clientes. A estruturação é realizada a partir dos requisitos de qualidade identificados no trabalho de "ouvir a voz do consumidor".

Nesse estudo, o trabalho de estratificação e agrupamento dos elementos de qualidade foi realizado seguindo os pressupostos de Akao (1996), no qual a organização dos requisitos de qualidade é realizada pelo método $\mathrm{KJ}$ que consiste em sistematizar e hierarquizar as informações por afinidade em três níveis: primário, secundário e terciário (Quadro 5).

Quadro 5 - Desdobramento da qualidade exigida - Processos e matéria prima

\begin{tabular}{|c|c|c|}
\hline \multicolumn{3}{|c|}{ AGRUPAMENTO DOS REQUISITOS DA QUALIDADE EXIGIDA - PROCESSOS } \\
\hline $1^{\circ}$ Nível & $2^{\circ}$ Nível & $3^{\circ}$ Nível \\
\hline \multirow{2}{*}{$\begin{array}{c}\text { Métodos e } \\
\text { procedimentos }\end{array}$} & Operação & $\begin{array}{l}\text { Padronização dos métodos de trabalho; } \\
\text { Instrução de trabalho; } \\
\text { Disciplina para seguir os métodos de trabalho. }\end{array}$ \\
\hline & Controle & $\begin{array}{l}\text { Plano de produção; } \\
\text { Pontos de controle e indicadores de desempenho; } \\
\text { Plano de inspeção. }\end{array}$ \\
\hline \multicolumn{3}{|c|}{ AGRUPAMENTO DOS REQUISITOS DA QUALIDADE EXIGIDA - MATÉRIA PRIMA } \\
\hline $1^{\circ}$ Nível & $2^{\circ}$ Nível & $3^{\circ}$ Nível \\
\hline \multirow[b]{2}{*}{ Matéria prima } & Qualidade & Qualidade da matéria prima para transformação; \\
\hline & Suprimentos & $\begin{array}{l}\text { Quantidade de matéria prima para transformação; } \\
\text { Prazo de entrega da matéria prima pelos fornecedores } \\
\text { externos; } \\
\text { Prazo de entrega da matéria prima pelos fornecedores } \\
\text { internos; }\end{array}$ \\
\hline
\end{tabular}

Fonte: Pesquisa (2010) 
A partir da configuração destas informações, organizou-se o instrumento de avaliação dos requisitos de qualidade. A avaliação objetivou identificar junto aos colaboradores da empresa, o grau de importância atribuído a cada elemento, bem como, avaliar suas atuais condições.

\subsection{Desdobramento dos elementos da qualidade}

A elaboração da tabela de desdobramento dos elementos da qualidade é realizada a partir das informações compiladas na tabela das qualidades exigidas (Figura 8). Os elementos da qualidade são características possíveis de mensuração para se avaliar a qualidade e possuem relação direta no atendimento da qualidade exigida pelos clientes (AKAO, 1996). É o primeiro passo do trabalho de conversão do mundo do cliente para a realidade técnica. A extração dos elementos da qualidade requer identificar, nas exigências expressas, características componentes que possibilitem seu atendimento.

A partir do entendimento de cada exigência de qualidade procura-se estabelecer condições de produto ou serviço que interfiram na garantia da qualidade. Nesse contexto são destacados os requisitos da qualidade exigida para processos e para matéria prima (Quadro 6).

Quadro 6 - Desdobramento dos Elementos de Qualidade - Processos e matéria prima

\begin{tabular}{|c|c|c|}
\hline \multicolumn{3}{|c|}{ AGRUPAMENTO DOS REQUISITOS DA QUALIDADE EXIGIDA - PROCESSOS } \\
\hline $1^{\circ}$ Nível & $2^{\circ}$ Nível & $3^{\circ}$ Nível \\
\hline \multirow{8}{*}{ Desenvolvimento } & \multirow{3}{*}{ Manutenção } & Manual de instruções \\
\hline & & Plano de produção \\
\hline & & Plano de inspeção \\
\hline & \multirow{5}{*}{ Aprimoramento } & Desenvolvimento de métodos \\
\hline & & Estudo de procedimentos \\
\hline & & Melhoria contínua \\
\hline & & Disciplina para seguir os métodos e procedimentos de trabalho \\
\hline & & Treinamento do operador \\
\hline \multicolumn{3}{|c|}{ AGRUPAMENTO DOS REQUISITOS DA QUALIDADE EXIGIDA - MATÉRIA PRIMA } \\
\hline $1^{\mathrm{o}}$ Nível & $2^{\circ}$ Nível & $3^{\circ}$ Nível \\
\hline \multirow{9}{*}{ Matéria Prima } & \multirow{5}{*}{ Garantia da qualidade } & Inspeção \\
\hline & & Controle da qualidade \\
\hline & & Conservação \\
\hline & & Conformidade \\
\hline & & Confiabilidade do fornecedor \\
\hline & \multirow{4}{*}{ Fornecimento } & Programação da produção \\
\hline & & Controle da produção \\
\hline & & Programação de compras \\
\hline & & Suprimento \\
\hline
\end{tabular}

Fonte: Pesquisa (2010)

Revista Produção Online, Florianópolis, SC, v.13, n. 2, p. 417-449, abr./jun. 2013. 


\subsection{Composição da matriz da qualidade}

A matriz da qualidade permite que as informações do ponto de vista do mercado e da empresa, sejam agrupadas e coordenadas para gerar produtos e serviços de qualidade (CHENG e MELO FILHO, 2007). Neste contexto foram construídas as matrizes da qualidade considerando a relação causa-efeito, que permeia o desenvolvimento do método QFD. Para tanto, agrupou-se as informações coletadas junto aos clientes internos, sobre os requisitos de qualidade das atividades de produção, e a partir das exigências foram definidos os elementos que possibilitam a efetivação da qualidade. Seguindo o propósito de definição de melhorias nos pontos falhos identificados foram configuradas duas matrizes de qualidade, uma para os processos e outra para a matéria prima, (Figuras 4 e 5).

O processo de correlação entre as tabelas foi realizado seguindo os preceitos de Akao (1996), Ohfuji; Ono e Akao (1997) e Cheng e Melo Filho (2007). Segundo os autores, a correlação é a atividade que expressa a relação existente entre os dois extremos: a exigência dos clientes e os elementos que atendem as exigências identificadas. Pelo método QFD a correlação é expressa por símbolos. Onde, o círculo duplo, (O) expressa forte correlação e possui peso 5 , o circulo simples $(\bigcirc)$ expressa correlação média e possui peso 3 , e o triângulo $(\triangle)$ possui peso 1 expressando uma correlação fraca. 
Figura 4 - Matriz da Qualidade - Processos

\begin{tabular}{|c|c|c|c|c|c|c|c|c|c|c|c|c|c|c|c|c|c|}
\hline \multirow{3}{*}{ 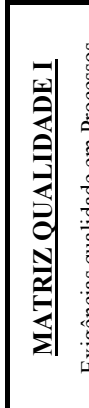 } & \multirow{3}{*}{ 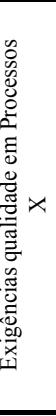 } & \multirow{3}{*}{ 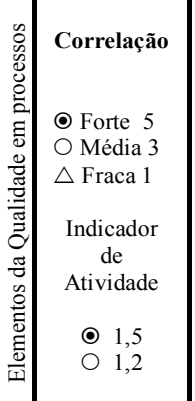 } & \multicolumn{8}{|c|}{ Desenvolvimento } & \multicolumn{7}{|c|}{ Planejamento da Qualidade } \\
\hline & & & \multirow[b]{2}{*}{ 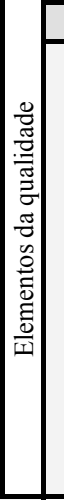 } & \multicolumn{2}{|c|}{ Manutenção } & \multicolumn{5}{|c|}{ Aprimoramento } & \multirow{3}{*}{ 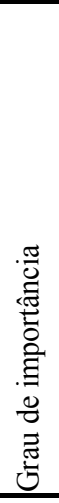 } & \multirow{3}{*}{ 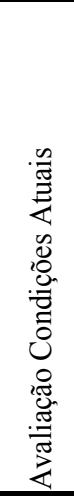 } & \multicolumn{3}{|c|}{ Plano } & \multicolumn{2}{|c|}{ Peso } \\
\hline & & & & \multirow{2}{*}{ 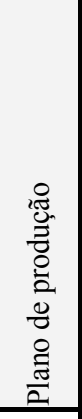 } & \multirow{2}{*}{ 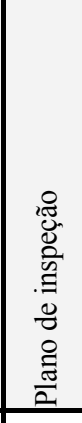 } & \multirow{2}{*}{ 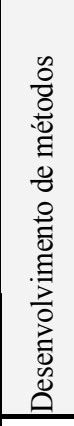 } & \multirow{2}{*}{ 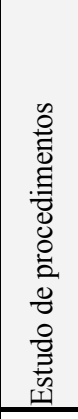 } & \multirow{2}{*}{ 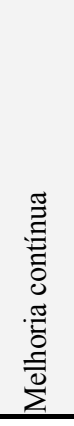 } & \multirow{2}{*}{ 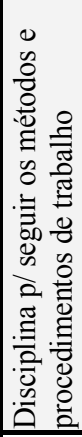 } & \multirow{2}{*}{ 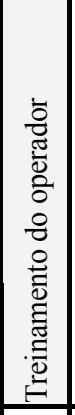 } & & & \multirow[t]{2}{*}{ 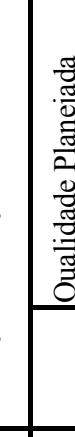 } & \multirow[t]{2}{*}{ 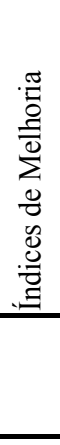 } & \multirow[t]{2}{*}{ 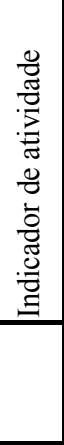 } & 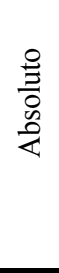 & $\begin{array}{l}\stackrel{0}{0} \\
0 \\
\frac{0}{0} \\
\approx \\
\approx\end{array}$ \\
\hline & Qualid: & lade exigida & 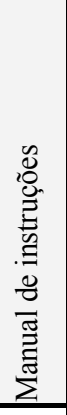 & & & & & & & & & & & & & $\begin{array}{l}\vec{n} \\
\infty \\
\infty\end{array}$ & \&. \\
\hline \multirow{6}{*}{ 告 } & \multirow{3}{*}{ 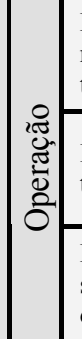 } & $\begin{array}{l}\text { Padronização dos } \\
\text { métodos de } \\
\text { trabalho }\end{array}$ & $0^{\infty}$ & $\triangleleft \hat{\bar{m}}$ & $0_{\substack{\infty \\
\Omega}}^{\infty}$ & $\circ \stackrel{\bar{a}}{=}$ & 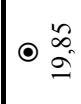 & $0^{\infty} \underset{\Omega}{\infty}$ & $\circ \stackrel{\bar{\sigma}}{=}$ & 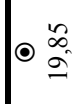 & $\hat{\mathrm{m}}$ & is & in & $\stackrel{\beta}{-}$ & $\odot \stackrel{2}{=}$ & $\vec{a}$ & $\begin{array}{l}8 \\
\stackrel{0}{0} \\
-\end{array}$ \\
\hline & & $\begin{array}{l}\text { Instruções de } \\
\text { trabalho }\end{array}$ & $\odot \stackrel{n}{\stackrel{n}{i n}}$ & $\triangleleft \stackrel{n}{\sim}$ & & $0 \stackrel{n}{g}$ & 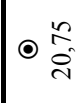 & $\triangleleft \stackrel{n}{*}$ & $\circ \stackrel{\text { ? }}{\underline{d}}$ & $\odot \stackrel{n}{\stackrel{2}{c}}$ & $\stackrel{n}{*}$ & $\stackrel{\circ}{m}$ & in & $\stackrel{8}{-}$ & $0 \cong$ & $\underset{\infty}{\infty}$ & 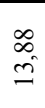 \\
\hline & & $\begin{array}{l}\text { Disciplina em } \\
\text { seguir os métodos } \\
\text { de trabalho }\end{array}$ & $\underset{\sim}{\sim}$ & & & $\triangleleft \vec{\sim}$ & $0 \stackrel{\substack{\mathrm{I} \\
\mathfrak{I}}}{ }$ & $\circ \stackrel{\substack{\mathfrak{I} \\
\mathfrak{I}}}{1}$ & $\odot \stackrel{n}{\stackrel{n}{n}}$ & $\circ \stackrel{n}{i}$ & $\vec{\sim}$ & त̃ & in & $\stackrel{n}{n}$ & $\odot \stackrel{2}{=}$ & $\hat{a}$ & $\hat{\overbrace{}}$ \\
\hline & \multirow{3}{*}{0} & Plano de produção & & $\odot \stackrel{n}{\stackrel{n}{i}}$ & $\odot \stackrel{n}{\stackrel{n}{+}}$ & & & & 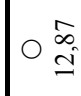 & & शे & $\stackrel{m}{m}$ & in & $\stackrel{\text { sे }}{\rightarrow}$ & $\odot \stackrel{n}{=}$ & $\stackrel{\overbrace{}}{\stackrel{2}{\varrho}}$ & 㐫 \\
\hline & & $\begin{array}{l}\text { Pontos de controle } \\
\text { e indicadores de } \\
\text { desempenho }\end{array}$ & & $0 \stackrel{n}{\stackrel{n}{n}}$ & ० $\stackrel{n}{\stackrel{n}{n}}$ & & & $\circ \stackrel{\mathrm{s}}{\underline{I}}$ & & $\odot \stackrel{n}{\stackrel{n}{2}}$ & $\vec{F}$ & $\stackrel{8}{i}$ & in & $\stackrel{:}{:}$ & $\odot \stackrel{2}{=}$ & $\stackrel{\overbrace{}}{\varrho}$ & $\stackrel{\infty}{\stackrel{\infty}{=}}$ \\
\hline & & Plano de inspeção & & $\odot \stackrel{n}{\underset{n}{n}}$ & $\odot \stackrel{n}{\stackrel{n}{i}}$ & & & & $\circ \stackrel{\text { ले }}{\text { ले }}$ & $\circ \stackrel{\text { ले }}{\mathrm{m}}$ & $\stackrel{f}{+}$ & $\stackrel{\infty}{m}$ & in & $\stackrel{n}{-}$ & $0 ?$ & $\stackrel{?}{\stackrel{f}{0}}$ & 离 \\
\hline \multicolumn{3}{|c|}{ PESO ABSOLUTO } & $\begin{array}{l}\vec{\infty} \\
\dot{f}\end{array}$ & $\begin{array}{l}\text { ה̂ } \\
\text { î. }\end{array}$ & $\begin{array}{l}8 \\
+ \\
+\infty\end{array}$ & $\begin{array}{l}n \\
\text { in } \\
\text { is }\end{array}$ & $\begin{array}{c}\text { ñ } \\
\hat{n}\end{array}$ & $\begin{array}{l}\vec{b} \\
\stackrel{\infty}{\sigma}\end{array}$ & $\stackrel{i n}{i}$ & $\begin{array}{l}g \\
g \\
\alpha\end{array}$ & 京 & & & & & & \\
\hline \multicolumn{3}{|c|}{ PESO RELATIVO (\%) } & $\infty$ & $\underset{f}{g}$ & 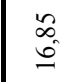 & $\hat{n}$ & 品 & $\stackrel{2}{a}$ & 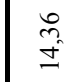 & $\frac{2}{2}$ & $\cong$ & & & & & & \\
\hline
\end{tabular}

Fonte: Pesquisa (2010)

O peso da correlação estabelecido pelo produto do resultado obtido na avaliação do grau de importância de cada elemento da qualidade é o valor definido para cada grau de correlação (AKAO, 1996; OHFUJI, ONO e AKAO, 1997; CHENG e MELO FILHO, 2007). 
Figura 5 - Matriz da Qualidade - Matéria prima

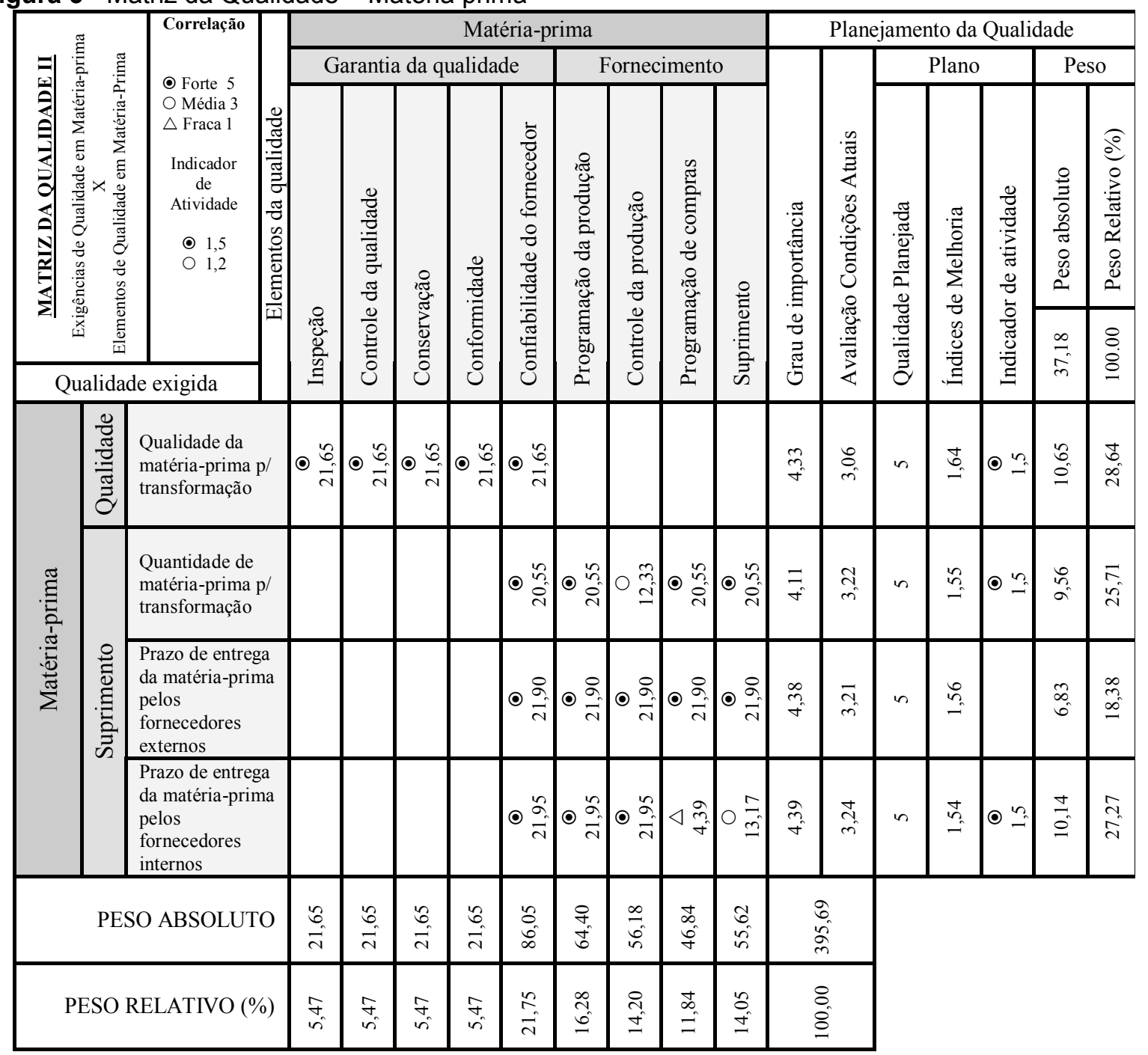

Fonte: Pesquisa (2010)

As exigências de qualidade foram expostas pelos integrantes do grupo constituído na empresa utilizando-se a técnica de brainstorming, de modo que o máximo de requisitos fosse identificado. Após, o trabalho de agrupamento e formação da tabela de exigências de qualidade, procedeu-se a avaliação do grau de importância e das condições atuais de cada exigência de qualidade. Neste processo utilizou-se o questionário, no qual cada entrevistado registrou sua resposta de acordo com pesos pré-estabelecidos para o grau de importância e para a avaliação das condições atuais. Optou-se em avaliar os quesitos com pesos de um a cinco, conforme os critérios (AKAO, 1996; e CHENG e MELO FILHO, 2007), expressos no Quadro 7.

Revista Produção Online, Florianópolis, SC, v.13, n. 2, p. 417-449, abr./jun. 2013. 
Quadro 7 - Critérios de avaliação das exigências de qualidade

\begin{tabular}{|l|l|l|l|}
\hline \multicolumn{3}{|c|}{ Grau de importância } & \multicolumn{2}{|c|}{ Condições atuais } \\
\hline 1 & Sem importância & 1 & Muito ruim \\
2 & Pouco importante & 2 & Ruim \\
3 & Importante & 3 & Regular \\
4 & Muito importante & 4 & Bom \\
5 & Extremamente importante & 5 & Muito bom \\
\hline
\end{tabular}

Fonte: Pesquisa (2010)

No trabalho de avaliação das exigências de qualidade procurou-se interagir com o maior número possível de colaboradores, participando 71 pessoas que fazem parte do processo produtivo. O resultado final da avaliação do grau de importância e das condições atuais foi conseguido por meio do cálculo da média aritmética de todas as respostas obtidas nos questionários de avaliação. No processo de planejamento da qualidade através das matrizes do QFD, estas informações são relevantes para a definição do peso absoluto e relativo de cada exigência.

$\mathrm{Na}$ composição do planejamento da qualidade, o valor da qualidade planejada é a importância que a empresa dará para cada exigência identificada. Sua definição deve considerar o grau de importância indicado pelos clientes e a atual situação da empresa em relação às exigências identificadas (OHFUJI, ONO e AKAO, 1997). Seguindo a doutrina do método QFD (AKAO, 1990), o coeficiente chamado índice de melhoria foi calculado dividindo o valor da qualidade planejada pelo resultado da avaliação das condições atuais da empresa. Este indicador exerce considerável influência na definição do peso relativo das exigências de qualidade da mesma forma que o indicador de melhoria.

$O$ indicador de melhoria foi estabelecido para reforçar a importância em relação a determinados itens considerados relevantes. O valor atribuído seguiu as determinações de Cheng e Melo Filho (2007). Segundo os autores, os itens que registram forte relevância são identificados pelo símbolo $\odot$ e recebem peso 1,5 . Os itens cuja relevância é média são caracterizados pelo símbolo $\bigcirc$ e recebem peso 1,2. Os itens que não representam importância relativa, não são simbolizados e não recebem peso. O cálculo do peso absoluto representa a quantificação de cada exigência de qualidade. $O$ resultado é o produto da multiplicação do grau de importância de cada exigência de qualidade pelo índice de melhoria e pelo indicador de melhoria (AKAO, 1996). A definição do peso relativo foi realizada pela conversão dos valores em cifras percentuais (análise horizontal das matrizes de qualidade), e a 
definição do peso absoluto dos elementos da qualidade (análise vertical das matrizes) realizou-se a partir do método de distribuição independente dos pontos (AKAO, 1996). Ou seja, o resultado foi obtido através da soma dos pesos de correlação estabelecidos na multiplicação entre o grau de importância atribuído para cada exigência de qualidade e o valor determinado para cada grau de correlação, seguindo a simbologia $\odot, \bigcirc$ e $\triangle$. A definição do peso relativo foi obtida pela conversão dos pesos absolutos em unidades percentuais.

\section{AÇÕES DE MELHORIA}

Depois de estruturados os dados, que compõem as matrizes de qualidade confirmou-se que, a utilização do método QFD possibilita quantificar e estruturar conceitos abstratos. A partir disso, e de posse dos resultados da análise, definiu-se as sugestões para a implementação da melhoria da qualidade das atividades de produção na indústria.

\subsection{Ações para melhoria da qualidade em processos}

O processo produtivo deve estar desenvolvido de maneira que previna a ocorrência de defeitos. Caso ocorram falhas, os custos das perdas e do retrabalho serão incorporados ao preço de venda do produto final e qualquer elemento que adicione custo e não valor ao produto deve ser alvo de investigação.

Após a análise, interpretação das informações compiladas na matriz da qualidade nos processos (Figura 4), verificou-se que os maiores pesos relativos dos itens avaliados nos elementos de qualidade, estão em: treinamento do operador, plano de inspeção, pontos de controle e indicadores de desempenho, disciplina em seguir os métodos de trabalho, padronização de métodos de trabalho e instruções de trabalho, conforme pode ser visualizado na Tabela 1.

Para atender a esses elementos de qualidade sugere-se a Implementação do Gerenciamento da Rotina dentro do método gerencial do ciclo do PDCA (Plan, Do, Check, Action). Método composto por quatro fases: planejar, executar, verificar e atuar corretivamente. Visando o controle e a obtenção de resultados eficazes e confiáveis nas atividades de uma organização promovendo a melhoria contínua, 
aperfeiçoando processos, possibilitando a redução de custos e o aumento da produtividade (PAGANI, RESENDE e MARÇAL, 2009; NING, CHEN e LIU, 2010).

Tabela 1 - Requisitos/Elementos da Qualidade com maior Peso Relativo - Processos

\begin{tabular}{l|c}
\hline \multicolumn{1}{c|}{ Requisitos da Qualidade } & Peso relativo \\
\hline Plano de inspeção & $17,83 \%$ \\
Plano de produção & $17,48 \%$ \\
Pontos de controle e indicadores de desempenho & $17,48 \%$ \\
Disciplina em seguir métodos de trabalho & $16,73 \%$ \\
Padronização dos métodos de trabalho & $16,60 \%$ \\
Instruções de trabalho & $13,88 \%$ \\
\hline \multicolumn{1}{c|}{ Elementos da Qualidade } & Peso relativo \\
\hline Treinamento do operador & $19,15 \%$ \\
Plano de inspeção & $16,85 \%$ \\
Plano de produção & $14,49 \%$ \\
Disciplina para seguir os métodos e procedimentos de trabalho & $14,36 \%$ \\
Estudo de procedimentos & $10,68 \%$ \\
Melhoria contínua & $9,75 \%$ \\
\hline
\end{tabular}

Fonte: Pesquisa (2010)

Para Campos (2004), em todos os níveis da organização as decisões devem se apoiar na análise de fatos, dados e informações dos ambientes interno e externo, abrangendo todas as partes interessadas. As medições devem refletir as necessidades e estratégias da organização e fornecer informações confiáveis sobre os processos e resultados. Assim, quando o domínio dos processos é pleno, há previsibilidade dos resultados, o que serve de base para a implementação das inovações e melhorias (PALADINI, 2004).

Campos (2004) salienta que, a busca pela excelência no gerenciamento deve começar por "arrumar a casa", ou seja, melhorar o Gerenciamento da Rotina do Trabalho. A sugestão do autor é padronizar os processos e o trabalho, de forma que cada pessoa assuma responsabilidades para o cumprimento das obrigações. Ainda, segundo Campos (2004), implantar o Programa 5'Ss é uma boa maneira de iniciar o processo de melhoria no Gerenciamento das Rotinas. Além de promover a sensibilização das pessoas para um ambiente de economia, organização, limpeza, higiene e disciplina, fatores fundamentais à produtividade, que potencializam o Gerenciamento da Rotina.

\subsection{Ações para melhoria da qualidade na matéria prima}

Através da leitura realizada na matriz da qualidade da matéria prima (Figura 5) observou-se significativa relevância em relação à qualidade da matéria prima para 
transformação (apresentação e conformidade com a especificação) aliada à confiabilidade do fornecedor e o cumprimento dos prazos de entrega pelos fornecedores, mais especificamente pelos fornecedores internos. Os pesos relativos mais significativos que subsidiaram a definição de diretriz para a melhoria da qualidade na matéria prima, (Tabela 2).

Tabela 2 - Requisitos e Elementos de Qualidade com maior Peso Relativo - Matéria Prima

\begin{tabular}{l|c}
\multicolumn{1}{c|}{ Requisitos de Qualidade } & Peso Relativo \\
\hline Qualidade da matéria prima para transformação & $28,64 \%$ \\
Prazo de entrega da matéria prima pelos fornecedores internos & $27,27 \%$ \\
Quantidade de matéria prima para transformação & $25,71 \%$ \\
Prazo de entrega da matéria prima pelos fornecedores externos & $18,38 \%$ \\
\hline \multicolumn{1}{c}{ Elementos da Qualidade } & Peso relativo \\
\hline Confiabilidade do fornecedor & $21,75 \%$ \\
Programação da produção & $16,28 \%$ \\
Controle da produção & $14,20 \%$ \\
Suprimento & $14,05 \%$ \\
Programação de compras & $11,84 \%$ \\
\hline Fonte: Pesquisa (2010)
\end{tabular}

Fonte: Pesquisa (2010)

A partir da interpretação destas informações verificou-se que, a qualidade da matéria prima e a confiabilidade do fornecedor apresentaram os maiores pesos relativos. Sugere-se a empresa, que seja adotado um sistema de Aprovação e Qualificação de Fornecedores, que proporcionará maior controle sobre os insumos e matérias primas adquiridos. A empresa inicia esse processo definindo o que será comprado e analisa detalhadamente cada uma das alternativas (fornecedores).

O estreitamento do relacionamento com fornecedores pode se materializar em ganhos de qualidade e na redução do custo total da compra. Os benefícios com a redução de custos decorrem da diminuição dos níveis de estoque dado o aumento da confiabilidade de entrega e da melhor gestão do desenvolvimento, produção e distribuição dos produtos negociados, propiciada pela coordenação conjunta das atividades, conduzida pelo contratado e contratante.

As relações de parceria são benéficas tanto o contratante, que passa a contar com fornecedores qualificados, menor custo de manutenção da base de fornecedores e um potencial ganho pela redução do custo total de compra, como o contratado que passa a ter uma demanda previsível e cativa, possibilitando a diminuição de custos ao longo de toda cadeia produtiva. Contudo, há que se 
considerar que o risco em relações um a um sempre aumenta, tanto para fornecedores quanto para clientes.

$\mathrm{Na}$ conclusão dos trabalhos de definição das ações para melhoria da qualidade nas atividades de produção, ressalta-se a sinergia de todas as ações definidas. Existe uma relação holística entre as ações sugeridas, o que comprova a relação causa efeito que permeia as decisões sobre melhorias da qualidade. Percebeu-se também, que o método QFD fornece informações relevantes ao processo decisório, por evidenciar um processo de subdivisão e unificação das exigências e elementos de qualidade e possibilitar uma ampla visibilidade dos fatores que afetam a qualidade.

\section{CONSIDERAÇÕES}

A análise pelo método QFD é complexa, pois existem diversas variáveis envolvidas, bem como vários critérios possíveis para a seleção das características desdobradas. Mesmo assim, o método mostrou-se eficiente no planejamento da qualidade, pois forneceu um diagnóstico da realidade que subsidiou a definição de ações para a melhoria da qualidade com vistas a atuar no processo produtivo e no combate ao desperdício.

Essas ações proporcionam melhoria da comunicação entre os setores interfuncionais, possibilitando, também, o fornecimento de produtos em conformidade com as especificações e com os requisitos dos clientes, nos prazos e quantidades corretas, a um custo mínimo, satisfazendo as pessoas envolvidas com a empresa. A prática dos fundamentos estudados acerca da qualidade e o QFD mostraram que:

1. A qualidade é elemento essencial para a competitividade das organizações. A melhoria da qualidade conduz a um aumento da produtividade e por consequência na lucratividade. Assim, a empresa que objetiva tornar-se competitiva precisa desenvolvê-la, não como um diferencial, mas como elemento imprescindível para manter-se no mercado de constantes transformações, onde as informações fluem rapidamente e interferem na decisão de compra do cliente.

2. A gestão da qualidade requer ações planejadas, com base em objetivos definidos, sendo necessário o contínuo controle das atividades de maneira a 
perceber desvios e providenciar os ajustes necessários, o que pode ser feito através do QFD.

3. O método QFD precisa ser sistêmico e a organização como um todo deve estar comprometida com o contínuo aperfeiçoamento dos produtos, processos, além do aperfeiçoamento dos colaboradores. Ações isoladas não surtirão o efeito necessário à garantia da qualidade em produtos e processos.

4. O QFD possibilitou avaliar o grau de importância e as condições atuais das exigências de qualidade identificadas. A partir da tabulação dos resultados obtidos, seguindo os preceitos de estruturação das matrizes da qualidade, foi possível estabelecer a correlação e definir o peso relativo das exigências e elementos de qualidade.

5. O método QFD, a partir da análise e interpretação das informações constantes nas matrizes de qualidade em processos e matéria-prima possibilitou a definição de ações para a melhoria da qualidade nas atividades produtivas, além de eliminar o desperdício ao longo do processo produtivo.

6. Resume-se que, o método QFD é aplicável a melhoria da qualidade dos processos e de produtos, neste estudo de caso, houve melhora na qualidade e redução dos desperdícios, devido o planejamento da qualidade por meio do QFD, que se torna mais rápida e fácil de programar.

Assim, o método QFD foi utilizado neste trabalho para a eliminação do desperdício. A questão do desenvolvimento do planejamento da qualidade através do QFD apresentou-se como ferramenta para a melhoria contínua de controle das atividades de maneira a perceber desvios e providenciar os ajustes necessários. Portanto, o método QFD pode ser utilizado pelos engenheiros de produção como ferramenta para a melhoria contínua do processo produtivo melhorando a qualidade e eficiência do processo com isso, eliminando o desperdício.

Assim, os princípios e métodos de desenvolvimento do QFD possibilitaram identificar quais os requisitos de qualidade exigidos pelos clientes internos e a partir deles extrair elementos que interferem na qualidade das atividades produtivas, principalmente o desperdício que ocorria ao longo do processo nessas atividades. 


\section{CONCLUSÕES}

O objetivo deste trabalho é a utilização do QFD para melhoria contínua dos processos produtivos e combate ao desperdício. A revisão da literatura foi importante, pois subsidiou a agregação do conhecimento e procedimentos para a utilização correta do método. A aplicação do QFD na empresa do setor metal mecânico mostrou que, este é um método indicado para melhoria contínua e auxilia no planejamento das atividades do processo, garantindo a qualidade dos produtos, evitando o retrabalho e o desperdício de material.

$\mathrm{Na}$ situação pesquisada a abordagem se refere, a um processo específico de uma organização metal mecânico, com suas características, e culturas individuais que a diferenciam de outras empresas. Mesmo assim, o trabalho pode ser tomado como modelo de aplicação do método, sempre considerando as peculiaridades próprias de cada processo e de cada empresa.

No processo, para utilização do método foi feita uma descrição da empresa, de seu ramo de atividade, de seu processo produtivo e gerencial, desde a entrada da matéria prima até o produto final. Assim que, se utilizou o QFD como método para ouvir o cliente interno e identificar os fatores que afetam a qualidade nas atividades produtivas, servindo para definir ações que envolvem a atuação desse cliente interno, e para que, essas pessoas conheçam melhor o setor e a organização em que trabalham. A partir desta percepção utilizou-se oQFD para o estabelecimento de estratégicas voltadas para as necessidades dos clientes internos, em melhorar as atividades ao longo do processo para evitar os desperdícios, além de desdobrá-las para todos os processos em todos os níveis da organização.

As informações fornecidas pelas matrizes mostram onde é necessário melhorar para facilitar a padronização dos processos e evitar o retrabalho agregando valor ao produto. Ainda, contribuiu para o gerenciamento do crescimento dos colaboradores, pois devido à participação destes na equipe, possibilitando as melhorias no processo produtivo, servindo de incentivo e valorização ao funcionário. Também um treinamento eficiente sobre o uso do QFD, foi fornecido aos colaboradores, sendo considerado um fator de sucesso durante sua implantação.

Por fim, salienta-se que as falhas apontadas com a realização do presente trabalho só serão sanadas se toda a equipe estiver engajada e comprometida com a Revista Produção Online, Florianópolis, SC, v.13, n. 2, p. 417-449, abr./jun. 2013. 
melhoria dos processos. Nesse sentido, sugere-se que sejam feitas reuniões periódicas entre as equipes para discutirem as falhas no processo para que sejam traçados planos de ação, que possibilitem a sua correção no momento da ocorrência.

Deve-se observar que, a limitação do trabalho, não esgota o assunto, além de alguns aspectos na questão da elaboração do questionário aplicado aos clientes internos, onde foram encontradas dificuldades para conseguir questionamentos capazes de medir as atividades executadas no processo, principalmente aquelas que apresentavam desperdícios, isso foi um grande desafio.

Nesta pesquisa ressalta-se a importância da avaliação por meio da observação "in loco" explorando profundamente as questões que envolviam a execução das atividades do processo de produção. Os dados obtidos também permitiram reavaliar e reestruturar diversos aspectos como: funcionários conhecerem a estrutura física, os equipamentos, as atividades, os materiais, o processo, os procedimentos e necessidades de treinamento, que são fundamentais para facilitar a prevenção de falhas com a finalidade de melhorar continuamente a qualidade do processo.

Finalmente, acredita-se que esta pesquisa possa contribuir para melhorar a compreensão dos problemas de outras empresas similares ou não a empresa pesquisada, apresentando problemas simples ou complexos no processo, quando atacados corretamente podem ser eliminados reduzindo custos e desperdícios. Assim, pode-se observar que, com pequeno investimento, a empresa obteve melhorias nos fatores relacionados ao processo produtivo, além de eliminar os desperdícios obteve um aumento significativo na sua produtividade e vantagem competitiva.

Esta pesquisa, além do aprendizado adquirido na implantação da metodologia QFD, acredita-se que é importante, a prática para os profissionais de engenharia de produção, neste caso está sendo divulgada, a combinação teórica prática para que seja utilizada por outros profissionais para que problemas aqui mostrados sejam evitados em empresas semelhantes ou não. 


\section{REFERÊNCIAS}

AKAO, Y. Quality function deployment: integrating customer requirements into product design. Cambridge: Productivity Press, 1990.

Introdução ao desdobramento da qualidade. Belo Horizonte: Fundação

Christiano Ottoni, Escola de Engenharia da UFMG, 1996.

CAMPOS, V.F. Gerenciamento da rotina do trabalho do dia-a-dia. 8. ed. Minas Gerais: INDG Tecnologia e Serviços Ltda., 2004.

CARNEVALLI, J.A.; MIGUEL, P.A.C. Revisão, análise e classificação da literatura sobre o QFD: tipos de pesquisa, dificuldades de uso e benefícios do método.

Gestão \& Produção, São Carlos, v. 14, n. 3, Dez 2007. Disponível em: $<$ http://www.scielo.br/scielo.php?script=sci_arttext\&pid=S0044-

$59672010000400006 \&$ Ing=en\&nrm=iso>. Acesso em: 19 jun. 2012. doi:

$10.1590 / S 0104-530 X 2007000300011$.

CHAN, L.K.; WU, M.L. A systematic approach to quality function deployment with a full illustrative example. Omega, v. 33, p. 119-139, 2005.

CHENG, L.C. QFD em desenvolvimento de produto: características metodológicas e um guia para intervenção. Revista Produção Online, v.3, n.2, 2003.

CHENG, L.C.; MELO FILHO, L.D.R. QFD: desdobramento da função qualidade na gestão de desenvolvimento de produtos. São Paulo: Editora Blucher, 2007.

DIAS JUNIOR, F.J.; MUNIZ JUNIOR, J.; CLARO, F.A. E.; NAKANO, D.N. Desdobramento da função qualidade (qfd) no desenvolvimento de projeto de treinamento: estudo exploratório para serviço. Revista Produção Online, v. $12, n^{\circ} 1$, 2012. Disponível em: <http://www.producaoonline.org.br/rpo/article/view/744/872>. Acesso em: 09 abr. 2012.

FERNANDES, J.M.R.; REBELATO, M.G. Proposta de um método para integração entre QFD e FMEA. Gestão \& Produção, São Carlos, v. 13, n. 2, 2006. Disponível em: <http://www.scielo.br/scielo.php?script=sci arttext\&pid=S0104530X2006000200007\&lng=en\&nrm=iso>. Acesso em: 17 ago. 2012. doi: 10.1590/S0104-530X2006000200007.

FINCH, B.J. OperationsNow.com: processes, value, and profitability. New York: McGraw-Hill, 2003.

GIL, A.C. Como elaborar projetos de pesquisa. 5. ed. São Paulo: Atlas, 2010.

HUAI, J. Develop IT outsourcing contract based on QFD. Management and Service Science, 2009. Disponível em:

<http://ieeexplore.ieee.org.ez47.periodicos.capes.gov.br/stamp/stamp.jsp?tp=\&arnu mber=5301696>. Acesso em: 12 abr. 2012. 
KRAJEWSKI, L.J.; RITZMAN, L.P.; MALHOTRA, M.K. Operation management: processes and value chains. 8. ed. Upper Saddle River, NJ: Pearson Education, 2007.

LEE, S.F.; Lo, K.K.; LEUNG, R.F.; KO, A.S.O. Strategy formulation framework for vocational education: Integrating SWOT analysis, balanced scorecard, QFD methodology and MBNQA education criteria. Managerial Auditing Journal, v. 15, n. 8, p. 407-423, 2000.

LIU, C.H. A group decision-making method with fuzzy set theory and genetic algorithms in quality function deployment. Quality \& Quantity. v. 44, n. 6, p. 11751189, 2009. Disponível em:

<http://www.springerlink.com.ez47.periodicos.capes.gov.br/content/x7l68v73441j3g7 6/fulltext.pdf>. Acesso em: 12 Abr 2012. doi: 10.1007/s11135-009-9304-1.

LUU, T.V.; KIM, S.Y; TRUONG, T.Q.; OGUNLANA, S.O. Quality improvement of apartment projects using fuzzy-QFD approach: A case study in Vietnam. KSCE Journal of civil engineering, p. 1226-7988, v. 13, n. 5, 2009.

LUCAS FILHO, F.C.; PIO, N.S.; FERREIRA, D.R. Método QFD como Ferramenta para Desenvolvimento Conceitual de Produtos de Madeiras da Amazônia. Acta Amazônica, Manaus, v. 40, n. 4, 2010. Disponível em: $<$ http://www.scielo.br/scielo.php?script=sci_arttext\&pid=S004459672010000400006\&lng=en\&nrm=iso>. Acesso em: 19 jun. 2011. doi: 10.1590/S0044-59672010000400006.

MELO FILHO, L.D.R.; CHENG, L.C. QFD na garantia da qualidade do produto durante seu desenvolvimento: caso em uma empresa de materiais. Produção, São Paulo, v. 17, n. 3, 2007. Disponível em: $<$ http://www.scielo.br/scielo.php?script=sci_arttext\&pid=S010365132007000300015\&lng=en\&nrm=iso>. Acesso em: 19 jun. 2012. doi: 10.1590/S0103-65132007000300015.

MIGUEL, P.A.C. QFD no desenvolvimento de novos produtos: um estudo sobre a sua introdução em uma empresa adotando a pesquisa-ação como abordagem metodológica. Produção, São Paulo, v. 19, n. 1, 2009. Disponível em: <http://www.scielo.br/scielo.php?script=sci_arttext\&pid=S010365132009000100008\&lng=en\&nrm=iso>. Acesso em: 21 ago. 2012. doi: 10.1590/S0103-65132009000100008.

The state-of-the-art of the brazilian QFD applications at the top 500 companies. International journal of quality \& reliability management: the leading edge in quality function deployment, v. 20, n. 1, p.74-89, 2003.

NASCIMENTO, C.A.A.; CHENG, L.C. Aplicação do QFD para identificar pontos críticos do processo de desenvolvimento de produtos a partir dos dados de assistência técnica - experimento em empresa de tecnologia da informação. In: CONGRESSO BRASILEIRO DE GESTÃO E DESENVOLVIMENTO DE PRODUTO, 2003, Gramado. Anais... Porto Alegre: Instituto Brasileiro de Gestão e Desenvolvimento de Produtos, 2003. 
NETO, E.P. Gestão da qualidade: princípios e métodos. 2. ed. São Paulo: Ed. Pioneira, 1992.

NING, J.F.; CHEN, Z.; LIU, G. PDCA Process Application in the Continuous Improvement of Software Quality. In: CONFERENCE ON COMPUTER, MECHATRONICS, CONTROL ELETRONIC AND ENGINEERING (CMCE), 2010.

OHFUJI, T.; ONO, M.; AKAO, Y. Método de desdobramento da qualidade. Belo Horizonte: Fundação Christiano Ottoni, Escola de Engenharia da UFMG, 1997.

OSORIO, J.C.; ARANGO, D.C.; RUALES, C.E. Selección de proveedores usando el despliegue de la función de calidad difusa. Revista EIA Escuela de ingenieria de Antioquia, n. 15, 2011. Disponível em:

<http://www.scielo.org.co/scielo.php?script=sci_arttext\&pid=S1794$12372011000100007 \&$ Ing=en\&nrm=iso >. Acesso em: 11 jun. 2012.

PAGANI, R.N.; RESENDE, L.M.; MARÇAL, R.F.M. Proposta de aplicação do método PDCA na estruturação de um SPL na região dos campos gerais, PR, Brasil. Revista Produção Online, v.9, n.2, p. 340-360, 2009. Disponível em:

$<$ http://www.producaoonline.org.br/index.php/rpo/article/viewFile/198/369>. Acesso em: 10 abr. 2012.

PALADINI, E.P. Gestão da qualidade: teoria e prática. 2. ed. São Paulo: Atlas, 2008.

PINNA, C.C.A.; CARVALHO, M.M. Gestão de escopo em projetos de aplicações web. Revista Produção Online, v. 8, $\mathrm{n}^{\circ}$ 1, 2008. Disponível em:

<http://www.producaoonline.org.br/rpo/article/view/25/19>. Acesso em: 12 Abr 2012.

PINTO, A.L.D.; PAIVA, C.L. Desenvolvimento de uma massa funcional pronta para tortas utilizando o método de Desdobramento da Função Qualidade (QFD). Ciência e Tecnologia de Alimentos, Campinas, 2011. Disponível em:

$<$ http://www.scielo.br/scielo.php?script=sci_arttext\&pid=S0101-

20612010000500007\&lng=en\&nrm=iso>. Acesso em: 19 jun. 2011. doi:

10.1590/S0101-20612010000500007.

PRASZKIEWICZ, I.K. Application of neural network in QFD matrix. Journal of Intelligent Manufacturing, 2011. Acesso em: 17 Abr 2012.

STEVENSON, W.J. Operations management, 9. ed. New York: McGraw-Hill Companies Inc., 2007.

VINODH, S.; RATHOD, G. Application of fuzzy logic-based environmental conscious QFD to rotary switch: a case study. Clean Technologies and Environmental Policy. v. 14, n. 2, p. 319-332, 2011. Disponível em: <http://www.springerlink.com.ez47.periodicos.capes.gov.br/content/v61811r9k46663 4j/fulltext.pdf>. Acesso em: 14 abr. 2012. doi: 10.1007/s10098-011-0404-y.

VOLPATO, L.F. et al. Planejamento da qualidade nas unidades de saúde da família, utilizando o Desdobramento da Função Qualidade (QFD). Cadernos de Saúde 
Pública, Rio de Janeiro, v. 26, n. 8, 2010. Disponível em:

$<$ http://www.scielo.br/scielo.php?script=sci_arttext\&pid=S0102-

311X2010000800010\&lng=en\&nrm=iso >. Acesso em: 19 jun. 2011. doi:

10.1590/S0102-311X2010000800010.

WAGNER, A. Utilização do método QFD como indutor de diretrizes para a melhoria da qualidade: um estudo de caso. Santa Maria, 2004. Dissertação (Mestrado em Engenharia da Produção). Universidade Federal de Santa Maria, 2004.

YANG, Y.O.; WANG, S.O.; DULAIMI, L.S.P. A fuzzy quality function deployment system for buildable design decisionmakings. Automation in Construction, v. 12, p. 381-393, 2003.

ZHAO, Z.; HOU, J. The study on Influencing Factors of Team Brainstorming Efectiveness. International Journal of Business and Management, v. 5, n. 1, p.181-184, 2010.

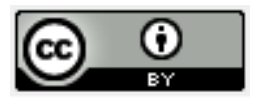

Artigo recebido em 09/04/2011 e aceito para publicação em 23/05/2013. 